\title{
Measurement of Impacts of Construction Land Expansion on Carbon Emissions in Hubei Province
}

\author{
Jing JIA \\ Department of Mechatronics Engineering, Wuhan Business University, Wuhan \\ 430056, PR China \\ email:jennydove1119@163.com
}

Keywords: Construction land expansion, Carbon emission, Measurement, Hubei Province.

\begin{abstract}
On the basis of STIRPAT model, this paper measures the influence that construction land expansion has on carbon emission from 2002 to 2012 in Hubei province by adopting the calculation method of carbon emission and the dynamic model of construction land. The research result: During the process of research, the construction land and carbon emission present the trend of growth. The construction land expansion has the dramatically positive effect on carbon emission; the carbon emission will increase $0.6 \%$ when the construction land increases $1 \%$. The research conclusion: To control the construction land expansion can help ease carbon emission. Therefore, this paper advises to control the size of construction land, strengthen the action of economical and intensive land use and build the constraint and evaluation mechanism of construction land carbon emission.
\end{abstract}

\section{Introduction}

The effects of land use change and other human activities on carbon emissions have been a research focus in the field of land science. Construction land is the most important investment of natural resources in the course of industrialization and urbanization, the gathering place of industries, population, construction and transportation, and the main carrier of carbon emissions. The continuous expansion of construction land indicates the increase of different kinds of construction activities for manufacturing and living, both of which may have a direct or indirect impact on carbon emissions [1,4,5]

Many scholars have made in-depth studies on the relationship between land use patterns \& structures carbon emissions, between land use changes and carbon emissions. Houghton et al [1,2] estimated via modeling the amount of carbon emissions brought about by global land use and cover change in different regions since the Industrial Revolution. Churkina [3] found that $80 \%$ of carbon emissions were contributed by cities. Du Guanyin [4] discovered that construction land expansion, population and per capita GDP are the main drivers of carbon emissions; construction land expansion has a significant positive impact on carbon emissions; adjustment of land use structure can inhibit or mitigate the impact on carbon emissions. Zhang Runsen et al[5].relied on the data of land use and energy consumption in Wuxi City from 1996 to 2008 to verify the inverted U-shaped relationship between the area of construction land and the intensity of carbon emissions. Hou Yanping [9], and Zhang Junfeng et al[12] found that carbon emissions contributed by construction land use accounted for over $99 \%$ of total carbon emissions in Wuhan, and that population, 
industrial land and transportation land were the main contributors of carbon emissions. However, rare studies have been made on the impacts of construction land expansion on carbon emissions at the provincial level, especially in Hubei province.

In the context of rapid industrialization and urbanization, construction land in Hubei Province expanded from $1418.74 \mathrm{~km} 2$ in 2002 to $1889.6 \mathrm{~km} 2$ in 2012, an annual growth rate of $3.3 \%$, which revealed a rapidly expanding trend. Carbon emissions surged from 60,647,500 tons in 2002 to 143,052,700 tons in 2012, an annual growth rate of $13.6 \%$. Both construction land and carbon emission have been showing a growth trend, which will cause a great impact on the ecological system in Hubei province. Therefore, research on the impacts of construction land expansion on carbon emissions is of great importance. In this paper, the author relied on data from Hubei Historical Statistics Yearbook (2002-2012), measured quantitatively via the STIRPAT model the impacts of construction land expansion on carbon emissions, providing a reference for the government to reduce carbon emissions through reasonable land use planning.

\section{Measurement Methods and Steps}

\section{Measurement of Construction Land Use Change}

The construction land use change is calculated according to the following Equation [11]:

$$
V_{c l}=\frac{S_{2}-S_{1}}{S_{1} T} .
$$

where $V_{c l}$ represents the annual change rate of construction land; $S_{1}$ and $S_{2}$ stand for the construction land area at the beginning and end of this research; while $T$ refers to the time span of this research.

\section{Measurement of Carbon Emissions}

Many scholars adopted the calculation methods [4,6,10] mentioned in the 2006 IPCC Guidelines for National Greenhouse Gas Inventories to measure the amount of regional carbon emissions. The energy sector is a prominent carbon-emission contributor, whose amount of carbon emissions accounted for over $90 \%$ of the total release. The amount of carbon emissions produced by industrial energy consumption in Hubei province was taken as the amount of carbon emissions. The calculation Equation is:

$$
Q_{c}=\sum_{i=1}^{8} E_{i} \times \delta_{i} .
$$

where $Q_{c}$ represents the total amount (unit: ten thousand tons) of carbon emissions; $E_{i}$ stands for the consumption of energies (including coal, coke, crude oil, fuel oil, gasoline, kerosene, diesel oil, and natural gas), while $\delta_{i}$ refers to the carbon emission coefficient of different kinds of energy, please refer to Table 1.

Table 1 Coefficients of Carbon Emissions of Different Energies

\begin{tabular}{|c|c|c|c|c|}
\hline Types of Energies & Coal & Coke & Crude oil & Fuel oil \\
\hline Carbon Emission Coefficient & 0.7559 & 0.8550 & 0.5857 & 0.6185 \\
\hline Types of Energies & Gasoline & Kerosene & Diesel oil & Natural Gas \\
\hline Carbon Emission Coefficient & 0.5538 & 0.5714 & 0.5921 & 0.4483 \\
\hline
\end{tabular}

Source: Zhang Leqin et al (2013) 


\section{Measurement of Impacts of Construction Land Expansion on Carbon Emissions}

Construct a STIRPAT-based model about the impacts of construction land expansion on carbon emissions in Hubei province, use SPSS17.0 software to make partial correlation analysis, then make principal component analysis to determine the elasticity coefficient of different driving factors to carbon emissions, namely the marginal effects of different driving factors on carbon emissions

The STIRPAT model is a stochastic model converted from the classic environmental stress model IPAT proposed by York et al (2004). This model is to study the influence of human factors on environmental stress and the relationship between environmental indicators and different driving factors like population, affluence and technology. The Equation is expressed as:

$$
I=a P^{b} A^{c} T^{d} \varepsilon .
$$

Where $I$ represents the environmental stress; a represents the model coefficient; $P, A$ and $T$ represents population, affluence and technology respectively; b, $c$ and $d$ represents the index of driving factors; $\varepsilon$ represents the error.

This paper attempts to use the STIRPAT model to study the impacts of construction land use change on carbon emissions in Hubei province; to choose the construction land area, per capita GDP, population, and per unit GDP energy consumption as the driving factors of carbon emissions in consideration of existing research results ${ }^{[6,10]}$ and good data availability; and thus to make a quantitative study on the influence effects of construction land expansion on carbon emissions.

\section{Data Source}

This paper selects data of energy consumption, construction land use, population, per capita GDP and per unit GDP energy consumption from 2002 to 2012 in Hubei province. Among them, energy consumption data derives from China Energy Statistical Yearbook over the years; construction land use refers to the built-up area of land; while data of built-up area, population, per capita GDP and per unit GDP comes from Hubei Statistical Yearbook over the years.

\section{Construction of Driving Factor model of Carbon Emissions}

\section{Model}

Construct a driving factor model of carbon emissions of Hubei province on the basis of STIRPAT model $[6,10]$ :

$$
Q_{c}=a P^{b} A^{c} T^{d} L^{g} \varepsilon
$$

Take the logarithm from Equation (5) and arrive at the Equation (6)

$$
\ln Q_{c}=e+b \ln P+c \ln A+d \ln T+g \ln L+f .
$$

where $Q_{c}$ represents the amount of carbon emissions (unit: ten thousand tons); $e$ and $f$ are the logarithmic values of $a$ and $\varepsilon ; P$ refers to the regional population (unit: 10,000); $A$ signifies the level of economy development in the region, represented by per capita GDP (Yuan/person); $T$ signifies the technical level, represented by per unit GDP energy consumption (tons of standard coal/million yuan); $L$ signifies the area of 
construction land in the region, represented by the built-up area $(\mathrm{km} 2) ; b, c, d$ and $g$ are the elasticity coefficients of corresponding factors, representing that when $P, A, T$ and $L$ change by $1 \%$, I will also change by $\mathrm{b} \%, \mathrm{c} \%, \mathrm{~d} \%$ and $\mathrm{g} \%$.

\section{Partial Correlation Analysis between Factors}

Use the SPSS17.0 software and get that the correlation coefficients of $L, P, A, T$ and $Q_{c}$ are $0.816,0.593,0.435$ and -0.975 correspondingly, indicating a positive correlation between carbon emission and construction land area, population, and per capita DGP, and a negative correlation between per unit GDP energy consumption and carbon emission.

\section{Coefficient Calculation}

Coefficient calculation of impacts of construction land use change on carbon emission in Hubei province.Carry out standardization processing of the influencing factors to eliminate the dimensional impact, then use SPSS 17.0 software to obtain the $Z Q_{c}, Z L$, $\mathrm{ZP}, \mathrm{ZA}$ and $\mathrm{ZT}$. Then, obtain Table 2 and 3 through principal component analysis (PCA) of carbon-emission driving factors.

Table 2 Total Square Deviations of PCA Explanation

\begin{tabular}{|l|l|l|l|l|l|l|}
\hline \multirow{2}{*}{$\begin{array}{l}\text { comp } \\
\text { onent } \\
\mathrm{s}\end{array}$} & \multicolumn{3}{|l|}{ Initial eigenvalue } & \multicolumn{2}{l|}{$\begin{array}{l}\text { Extractiong and loading of the sum } \\
\text { of squares }\end{array}$} \\
\cline { 2 - 7 } & Total & $\begin{array}{l}\text { Varianc } \\
\mathrm{e} \%\end{array}$ & $\begin{array}{l}\text { Accumulat } \\
\text { ive\% }\end{array}$ & Total & $\begin{array}{l}\text { Variance } \\
\%\end{array}$ & $\begin{array}{l}\text { Accumulat } \\
\text { ive\% }\end{array}$ \\
\hline 1 & 3.076 & 76.897 & 76.897 & 3.076 & 76.897 & 76.897 \\
\hline 2 & 0.799 & 19.963 & 96.860 & & & \\
\hline 3 & 0.113 & 2.825 & 99.685 & & & \\
\hline 4 & 0.013 & 0.315 & 100.00 & & & \\
\hline
\end{tabular}

Extraction method: PCA

Table 3 PCA Coefficient

\begin{tabular}{|l|l|l|l|l|l|l|l|}
\hline & & Zscore $(\mathrm{L})$ & Zscore(P) & Zscore(A) & $\begin{array}{l}\text { Zscore(T } \\
)\end{array}$ & & \\
\hline Component & 1 & 0.835 & -0.667 & 0.995 & -0.972 & & \\
\hline
\end{tabular}

Extraction method: PCA

According to the results, we can extract a main component $\mathrm{F}$ whose cumulative variance is $76.7 \%$, obtaining the relationship between aggregate variable and the original variable:

$$
F=0.835 Z L-0.667 Z P+0.995 Z A-0.972 Z T \text {. }
$$

Then, perform a two-stage least square regression according to the aggregate variable and the amount of carbon emissions. $z Q_{c}$ is the explained variable, and $F$ the explaining variable. Table 4 and Table 5 are thus obtained.

Table 4 ANOVA Results

\begin{tabular}{|l|l|l|l|l|l|}
\hline & $\begin{array}{l}\text { Sum of } \\
\text { squares }\end{array}$ & df & Mean Square & F & Sig \\
\hline Equation 1 Regression & 9.435 & 1 & 9.435 & 150.501 & 0.000 \\
\hline Residual & 0.564 & 9 & 0.063 & & \\
\hline Total & 9.999 & 5.610 & & & \\
\hline
\end{tabular}


Table 5 Model Coefficients

\begin{tabular}{|l|l|l|l|l|l|}
\hline & \multicolumn{2}{|l|}{ Unstandardized Coefficient } & & & \\
\hline & B & Standard Error & Beta & t & sig \\
\hline Equation1Constant & $5.652 \mathrm{E}-16$ & 0.075 & & $7.487 \mathrm{E}-15$ & 1.000 \\
\hline F & 0.316 & 0.026 & 0.971 & 12.268 & 0.000 \\
\hline
\end{tabular}

In Table 4ANOVA Results, the F value is 150.501 and sig value is less than 0.01 , indicating a good model fitting. The Equation (8) of aggregate variable and $Z Q_{c}$ can be obtained from Table 5. Since the sig. value of constant is 1 , the constant can be deleted:

$$
Z Q_{c}=0.316 F .
$$

Put Equation (7) into Equation (8) to arrive at Equation (9):

$$
Z Q_{c}=0.264 Z L-0.211 Z P+0.314 Z A-0.307 Z T \text {. }
$$

According to Table 2 and the Equation of standardization processing, Equation (9) can be converted to Equation (10):

$$
\ln Q_{c}=h+0.600 \ln L-2.75 \ln P+0.163 \ln A-0.023 \ln T
$$

where $h$ is a constant, the sum of $e$ and $f$ in Equation (6); from Equation (10) we can obtain the STIRPAT model about the influencing effect of construction land use change on carbon emission in Hubei province:

$$
Q_{c}=h P^{-2.75} A^{0.163} T^{-0.023} L^{0.600} \text {. }
$$

With the STIRPAT model Equation (11), we can obtain that the coefficients of $P, A$, $T$ and $L$ are $-2.75,0.163,-0.023$ and 0.6 respectively. The figures indicate that if the construction land and per capita GDP increase by $1 \%$, the amount of carbon emissions will increase by $0.6 \%$ and $0.163 \%$. They also indicate that there is an incremental effect of construction land expansion and economic growth on the amount of carbon emissions in Hubei province. Hubei is a province with a strong outflow of population; so its population is relatively stable although sometimes declining. Therefore, there is no incremental effect of population increase on carbon emission. Moreover, the reduction of per unit GDP energy consumption has a decremental effect on carbon emissions. From the greatest influencing coefficient of construction land use on carbon emissions, we can see that there is a positive correlation between construction land use and carbon emission from 2002 to 2012.

\section{Conclusions}

The results of STIRPAT model-based measurement of impacts of construction land expansion on carbon emission showed that with the expansion of construction land use during the decade from 2002 to 2012, the amount of carbon emission rose swiftly. There exists the most significant incremental effect of construction land expansion on carbon emission, consistent with the development trend of urbanization and industrialization. Therefore, controlling the expansion scale of construction land will help alleviate and reduce the amount of carbon emissions. Based on the research results, the following policy suggestions are proposed: (1) transform the economic development mode, accelerate the transformation to the energy-saving industrial structure, and promote the low-carbon urbanization path in Hubei province; (2) strictly implement the land use policies and follow land use regulations, strictly control the 
scale of construction land, modify land-use laws and regulations, severely punish violating behaviors in construction land use. (3) improve the layout of construction land use, and make arrangements for various types of land use; step up efforts to implement optimal and intensive land use measures, encourage the cluster development of industrial projects, and guide toward the intensive use of urban land; (4) establish an optimal and intensive land use evaluation system for the goal of low-carbon development, and establish a construction land carbon emission constraint and assessment mechanism.

\section{Acknowledgment}

This research was supported by Hubei provincial Department of Education Science research directive project of the Measurement of poverty level of urban residence in Wuhan.(Project No. B2015387)

\section{References}

[1] Houghton R A, Hobbie JE, Mellilo JM ,etal .Changes in the carbon content of terrestrial biota and soils between 1860and 1980: A net release of CO2 to the atmosphere [J].EcologicalMonographs, 1983, 53(3): 235-262

[2] Houghton R A, Lefkowitz D S, Skole D L. Changes in the landscape of Latin America between 1850-1980(2): Net increase of CO2 to the atmosphere [J].Forest Ecology and Management,1991, 38: 173-199

[3] Churkina G.modeling the carbon cycle urban systems [J].Ecological Modeling,2008,216(2):107-113

[4] Du Guanyin. A study on the impacts of contruction land on carbon emissions[J].China Land Science.2010(5):32-36

[5] Zhang Runsen, Pu Lijie, Wen Ji-qun, Xu Yan, Hypothesis and Validation on the Kuznets Curve of Construction Land Expansion and Carbon Emission Effect[J], Journal of Natural Resources2012(5):(723-733)

[6] Zhang Le Qing,Chen Su Ping,Wang Wen Qin,et al.Measurement and trend analysis of carbon emissions from construction land changes in Anhui in the recent 15 years-Based on STIRPAT model [J]. Acta Scientiae Circumstantiae,2013.33( 3) : 950-958

[7] Turner B L,Lambin E F,Reenberg A.2007.The emergence of land change science for global environmental changeand sustainability [J].Proceedings of the National Academy of Sciences of the UnitedStates of America,104( 52) : 20666-20671

[8] Boyle R, Mohanmed R.2007.State growth management, smart growth and urban containment: A review of the US and a study of the heartland [J]. Journal of Environmental Planning and Management, 50 (5):677-697

[9] Hou Yanping, A study on the temporal characteristics and influential factors of land-use carbon emission in Wuhan [M], Huazhong Agricultural University Master's Degree Dissertation.2014.6

[10]IPCC, OECD, IEA. Revised 1996 IPCC Guidelines for National Green House Gas Inventories [R].IPCC, Bracknell, 1996, Vol 21. 
[11] Gu Chaolin, Tan Zongbo, Liu Wan, et al.A study on climate change, carbon emissions and low-carbon city planning. Urban Planning Forum, 2009(3): 38-45.

[12]Zhang junfeng, Zhang anlu, Dong jie, Carbon emission effect of land use influencing factors decomposition of carbon emission in wuhan urban agglomeration.Resource and Environment in the Yangtze Basin.2014(5):596-602 